\title{
Parâmetros digestivos e produção de proteína microbiana em novilhas em crescimento compensatório
}

[Digestive parameters and protein microbial production in heifers under compensatory growth]

\author{
P.B. Costa $^{1}$, A.C. Queiroz $^{2}$, A.L.R. Magalhães ${ }^{3}$, K. Zorzi $^{4}$, R.O. Mello ${ }^{4}$, A.A.M.A. Oliveira ${ }^{1}$ \\ ${ }^{1}$ Centro de Ciências Agrárias - UNIOESTE - Marechal Cândido Rondon, PR \\ ${ }^{2}$ Departamento de Zootecnia - UFV - Viçosa, MG \\ ${ }^{3}$ Departamento de Veterinária - UNIC - Cuiabá, MT \\ ${ }^{4}$ Aluno de pós-graduação - UFV - Viçosa, MG
}

\begin{abstract}
RESUMO
Avaliaram-se o manejo para crescimento compensatório e o efeito da suplementação com ionóforo na dieta sobre os parâmetros digestivos e sobre a produção de proteína microbiana de novilhas leiteiras. Foram utilizadas 20 animais puros da raça Pardo-Suíça, com média de peso inicial de $200 \mathrm{~kg}$ aos cinco meses de idade. Os tratamentos foram arranjados em um esquema fatorial $2 \times 2 \times 2$, e os animais foram alocados, aleatoriamente, em cada uma das combinações. O fator 1 consistiu dos sistemas de alimentação (convencional e crescimento compensatório), o fator 2, da utilização (200mg de monensina/animal/dia) ou não de ionóforo e o fator 3 , dos períodos de alimentação (P1 e P2). A inclusão de ionóforo na dieta aumentou os coeficientes de digestibilidade total da matéria seca, da matéria orgânica, dos carboidratos totais e da fibra em detergente neutro. Não houve efeito do sistema de alimentação, da adição de ionóforo à dieta e do período sobre a produção microbiana. A eficiência microbiana (g PB microbiana/kg de NDT consumido) no período de restrição foi maior que no período de realimentação.
\end{abstract}

Palavras-chave: novilhas leiteiras, monensina, produção microbiana, realimentação, restrição

\begin{abstract}
The effects of compensatory growth and ionophore supplementation of diet of dairy heifer on digestive parameters and protein microbial production were evaluated. Twenty five-month-old Brown-Swiss heifers averaging $200 \mathrm{~kg} \mathrm{b.w.} \mathrm{were} \mathrm{used.} \mathrm{The} \mathrm{treatments} \mathrm{were} \mathrm{arranged} \mathrm{in} \mathrm{a} \mathrm{factorial} \mathrm{design} \mathrm{(2 \times 2 \times 2)} \mathrm{with} \mathrm{the} \mathrm{animals}$ randomly allocated to each of the combinations. Factor 1 was based on the feeding systems (conventional and compensatory growth), factor 2 on ionophore supplementation option (200mg of monensin/animal/day or not) and factor 3, on the feeding periods (P1 and P2). The diet supplemented with ionophore increased the total digestibility coefficients of dry matter, organic matter, total carbohydrates, and neutral detergent fiber. No effect of feeding systems, ionophore supplementation, or feeding periods based on microbial production was oberved. The microbial efficiency ( $\mathrm{g}$ of microbial crude protein $/ \mathrm{kg}$ of NDT intake) during the restriction period was higher than the re-feeding period.
\end{abstract}

Keywords: dairy heifer, monensin, microbial production, realimentation, restriction

\section{INTRODUÇÃO}

Desde a década de 70, antibióticos carboxílicos, inibidores da síntese de ácidos nucléicos

Recebido em 5 de junho de 2006

Aceito em 1 de agosto de 2008

Endereço para correspondência (corresponding address)

Rua Presidente Costa e Silva, 1125/03

86950-000 - Marechal Cândido Rondon, PR

E-mail: patriciabarc@ibest.com.br

Apoio: $\mathrm{CNPq}$ microbianos, têm sido extensivamente utilizados na manipulação da fermentação ruminal com o objetivo de aumentar a digestibilidade da dieta e, conseqüentemente, o ganho de peso de animais em crescimento (Zinn et al., 1994; Russell e Strobel, 1989). 
Esses aditivos nutricionais, denominados ionóforos, são produtos da fermentação de diversas sepas de actinomyces e de streptomyces e, além de apresentarem toxicidade sobre bactérias gram-positivas, possuem efeito sobre protozoários, fungos e organismos superiores (Russell e Strobel, 1989). Seu modo de ação tem sido discutido em revisões de literatura (Schelling, 1984; Spears, 1990), mas, de forma simplificada, esses produtos atuam aumentando a produção de ácido propiônico e reduzindo a dos ácidos lático e butírico, resultando em incremento no suprimento de metabólicos-chave para o crescimento. Esses efeitos combinados podem melhorar a performance reprodutiva de novilhas pelo aumento da fertilidade (Beckett et al., 1998). Além disso, os antibióticos carboxílicos podem ser efetivos na prevenção de laminite e cetose bovina.

Nos últimos anos, ionóforos, como a monensina sódica (Leopoldino et al., 2007), têm sido utilizados na formulação de dietas para manejo que alterna períodos de restrição energética e períodos de realimentação, com o objetivo de auxiliar a promover o crescimento compensatório nos animais, diminuindo os custos relativos à criação de novilhas para reposição do rebanho.

Entretanto, o desenvolvimento de eficientes estratégias para maximizar o retorno econômico da atividade leiteira depende do melhor entendimento dos efeitos do manejo para crescimento compensatório e da utilização de ionóforos no metabolismo animal.

Este trabalho teve o objetivo de avaliar o efeito do manejo para crescimento compensatório e da inclusão de monensina na dieta sobre os parâmetros digestivos e produção de proteína microbiana de novilhas leiteiras.

\section{MATERIAL E MÉTODOS}

O experimento foi realizado durante o período de abril a setembro de 2004 .

Foram utilizadas 20 novilhas puras da raça Pardo-Suíça, com média de cinco meses de idade e peso inicial aproximado de $200 \mathrm{~kg}$. Os tratamentos foram arranjados em um esquema fatorial $2 \times 2 \times 2$, e os animais foram alocados, aleatoriamente, em cada uma das combinações.
O fator 1 consistiu de dois sistemas de alimentação, convencional e de crescimento compensatório; o fator 2 , da utilização ou não de ionóforo, $200 \mathrm{mg}$ de monensina/animal/dia; e o fator 3, dos períodos de alimentação (P1 e P2). Os animais do sistema convencional receberam alimentação ad libitum, com dieta formulada para atender às recomendações nutricionais propostas pelo NRC (Nutrient..., 2001), enquanto os em crescimento compensatório foram submetidos a um manejo nutricional com dois períodos distintos: no primeiro - período de restrição, 90 dias -, o consumo de matéria seca (CMS) foi limitado a $2,5 \%$ do peso corporal (PC) e a dieta continha $25 \%$ menos energia metabolizável (EM) que a dieta do sistema convencional; no segundo - período de realimentação, 60 dias-, a oferta de MS e a EM da dieta foi igual à do grupo do sistema convencional.

A duração do período experimental foi de 180 dias, sendo os 30 primeiros destinados à adaptação dos animais. Os animais foram alojados em baias individuais, parcialmente cobertas, onde tiveram acesso permanente ao alimento e à água. A alimentação foi oferecida duas vezes ao dia, às 7 e 17h, permitindo-se sobras de, no máximo, $10 \%$ para os sistemas convencional e de crescimento compensatório no período de realimentação. A dieta foi calculada para que todos os animais, independentemente do tratamento, recebessem a mesma quantidade de PB em todos os períodos. A proporção dos ingredientes nas dietas encontra-se na Tab. 1.

Diariamente, foram registradas as quantidades dos alimentos fornecidos e das sobras, para estimativa do consumo, sendo elaboradas amostras compostas da dieta e das sobras, por animal e por período, que foram congeladas, para análises posteriores. Nos alimentos, foram determinadas as concentrações de matéria seca (MS), nitrogênio total (NT), extrato etéreo (EE) e cinzas (CZ), utilizando-se as técnicas descritas por Silva e Queiroz (2002); de fibra em detergente neutro (FDN) e de fibra em detergente ácido (FDA), segundo Van Soest et al. (1991), e de lignina em ácido sulfúrico (LDA), de acordo com técnica descrita por Pereira e Rossi Jr. (1995). As sobras foram analisadas para determinação dos teores de MS, NT, EE, CZ e FDN. 
Tabela 1. Proporção dos ingredientes nas dietas experimentais de novilhas leiteiras, com base na matéria seca, de acordo com o sistema de alimentação, com ou sem suplementação ionóforo

\begin{tabular}{|c|c|c|c|c|}
\hline \multirow{2}{*}{ Alimento } & \multicolumn{2}{|c|}{ Convencional } & \multicolumn{2}{|c|}{ Crescimento compensatório } \\
\hline & sem ionóforo & com ionóforo & sem ionóforo & com ionóforo \\
\hline & \multicolumn{4}{|c|}{ Período de restrição $(\mathrm{P} 1)$} \\
\hline Feno tifton 85 & 60,00 & 60,00 & 60,00 & 60,00 \\
\hline Milho, grão moído & 15,31 & 15,31 & 2,10 & 2,10 \\
\hline Farelo de algodão & 23,29 & 23,29 & 36,20 & 36,20 \\
\hline Calcário calcítico & 0,60 & 0,60 & 1,00 & 1,00 \\
\hline \multirow[t]{2}{*}{ Mistura mineral $^{1}$} & 0,80 & 0,80 & 0,70 & 0,70 \\
\hline & \multicolumn{4}{|c|}{ Período de realimentação $(\mathrm{P} 2)$} \\
\hline Feno tifton 85 & 60,00 & 60,00 & 50,00 & 50,00 \\
\hline Milho, grão moído & 15,10 & 15,10 & 20,10 & 20,10 \\
\hline Farelo de algodão & 23,50 & 23,50 & 28,50 & 28,50 \\
\hline Calcário calcítico & 0,60 & 0,60 & 0,60 & 0,60 \\
\hline Mistura mineral $^{1}$ & 0,80 & 0,80 & 0,80 & 0,80 \\
\hline
\end{tabular}

${ }^{1}$ Composição percentual: Ca 14\%; P 9\%; S 2,5\%; Mg 2,5\%; Zn 0,55\%, Cu 0,15\%.

Os teores de carboidratos solúveis em detergente neutro (CSDN) foram obtidos a partir da equação: $\mathrm{CSDN}=100-(\% \mathrm{~PB}+\% \mathrm{EE}+\% \mathrm{CZ}+$ $\%$ FDN), segundo Van Soest et al. (1991).

A concentração de energia dos alimentos foi estimada segundo Van Soest (1994), utilizandose a equação: NDT $=$ DMS - cinzas $+1,25 \mathrm{x}$ (EE) $+1,9$, em que DMS é a digestibilidade da matéria seca, obtida como: DMS $=(100-$ FDN $) * 0,98+($ FDN*DFDN/100) $-12,8$. DFDN é a digestibilidade estimada da FDN, calculada como: $\quad$ DFDN $=147,3-78,9 \quad \log _{10}$ [(LDA/FDA)*100], em que LDA representa o conteúdo de lignina do alimento. A conversão dos valores de NDT para energia metabolizável (EM) foi realizada por meio da equação: EM $(\mathrm{Mcal} / \mathrm{kg})=1,01 \mathrm{x} \mathrm{ED}(\mathrm{Mcal} / \mathrm{kg})-0,45, \mathrm{em}$ que ED é o teor de energia digestível, obtido como: $\mathrm{ED}(\mathrm{Mcal} / \mathrm{kg})=0,04409 \mathrm{x}$ NDT $(\%)$. Ambas as equações foram propostas pelo NRC (Nutrient..., 2001).

Para se estimar o valor de energia das dietas, foram utilizados os dados de digestibilidade obtidos neste experimento, sendo: NDT $(\%)=$ $\mathrm{dCSDN}+\mathrm{dPB}+(\mathrm{dEE} \times 2,25)+\mathrm{dFDN}$, em que "d" representa a digestibilidade dos diferentes componentes.

Os três dias que antecederam o término dos períodos de restrição e realimentação foram utilizados para determinação da digestibilidade dos alimentos. No primeiro, segundo e terceiro dias, respectivamente, às oito, 12 e 16 horas, foram coletadas amostras de fezes diretamente do reto. As amostras foram pré-secas em estufa de ventilação forçada, a $60^{\circ} \mathrm{C}$ por 72 horas, e processadas em moinho de faca com peneira de crivos de $1 \mathrm{~mm}$, elaborando-se uma amostra composta por animal, com base no peso seco de cada subamostra.

Para determinação da produção de matéria seca fecal, foi utilizada a fibra em detergente ácido indigestível (FDAi) como indicador interno, conforme técnica descrita por Cochran et al. (1986). Realizou-se a incubação ruminal em sacos de ankon (filter bags F57), por 144 horas, em vez de usar a digestibilidade in vitro, sugerida no protocolo original. Foram incubadas amostras das sobras, das fezes e dos ingredientes utilizados nas dietas. O material remanescente da incubação foi submetido à fervura em detergente ácido por uma hora e o resíduo foi considerado FDAi.

No $85^{\circ}$ e $145^{\circ}$ dias do período experimental, alíquotas de $50 \mathrm{ml}$ de urina foram obtidas de todos os animais, aproximadamente quatro horas após a alimentação, durante a micção, estimulada por massagem na vulva. A urina foi filtrada $\mathrm{e}$ alíquotas de $10 \mathrm{ml}$ foram retiradas e diluídas imediatamente em $40 \mathrm{ml}$ de ácido sulfúrico a $0,036 \mathrm{~N}$ e armazenadas $\mathrm{a}-15^{\circ} \mathrm{C}$, para posteriores análises dos níveis de uréia, alantoína e ácido úrico. Uma amostra de urina pura foi armazenada para determinação das concentrações de compostos nitrogenados totais e de creatinina. Os teores de creatinina e uréia foram determinados, respectivamente, pelo sistema colorimétrico com reação de ponto final e pelo método diacil 
modificado (kits comerciais). Adotou-se a seguinte equação para determinação da excreção diária de creatinina (EDC): $\mathrm{EDC}(\mathrm{mg} / \mathrm{kgPC})=$ 32,27-0,01093*PC (Chizzotti, 2004).

As análises dos níveis de alantoína e de ácido úrico na urina foram feitas pelo método colorimétrico, conforme metodologia descrita por Chen e Gomes (1992). A excreção total de derivados de purinas (DP) foi calculada pela soma dos níveis de alantoína e ácido úrico excretados na urina. As purinas absorvidas (Pabs, $\mathrm{mmol} /$ dia) foram estimadas a partir da excreção de derivados de purinas (DP, mol/dia) por meio da equação: $\mathrm{DP}=0,84 *$ Pabs $+0,236 * \mathrm{PC}^{0,75}$, em que 0,84 é a recuperação das purinas absorvidas como derivados de purina, e $0,236 * \mathrm{PC}^{0,75}$, a excreção endógena de derivados de purinas (Orellana et al., 2001). A síntese ruminal de compostos nitrogenados (Nmic, gN/dia) foi determinada considerando-se as purinas absorvidas (Pabs, mmoldia), por meio da equação: $\mathrm{Nmic}=(70 * \mathrm{Pabs}) /(0,83 * 0,134 * 1000)$ (Chen e Gomes, 1992), em que 70 é o conteúdo de $\mathrm{N}$ das purinas $(\mathrm{mgN} / \mathrm{mol}) ; 0,83$, a digestibilidade intestinal das purinas microbianas; e 0,134 , a razão $\mathrm{N}$ purina: $\mathrm{N}$ total nas bactérias (Valadares et al., 1999).
As variáveis relacionadas ao consumo e à digestibilidade da matéria seca e dos nutrientes e à produção de proteína microbiana foram submetidas à análise de variância, por meio de modelos que contêm os efeitos de sistema (SIS), ionóforo (ION) e período (PER), além das interações dessas fontes de variação (efeitos fixos) e do resíduo (efeito aleatório), utilizandose o PROC GLM do SAS (User's..., 2000).

Quando necessário e na presença de efeitos significativos das interações, os efeitos de sistema e ionóforo foram analisados dentro de cada período. As diferenças entre as fontes de variação foram estimadas por meio de contrastes, aplicando-se o teste $t$ de Student para verificar se as diferenças eram significativas.

\section{RESULTADOS E DISCUSSÃO}

As médias de consumo de matéria seca (CMS), matéria orgânica (CMO), fibra em detergente neutro (CFDN), carboidratos totais (CCT), carboidratos solúveis em detergente neutro (CCSDN) e energia metabolizável (CEM), estudadas dentro de cada período, são apresentados na Tab. 2.

Tabela 2. Médias e diferenças entre os sistemas convencional e crescimento compensatório (comp.), em cada período $(\mathrm{P})$, para os consumos de matéria seca (CMS), matéria orgânica (CMO), fibra em detergente neutro (CFDN), carboidratos totais (CCT), carboidratos solúveis em detergente neutro (CCSDN) e energia metabolizável (CEM)

\begin{tabular}{lcccccccc}
\hline \multirow{2}{*}{ Item } & \multicolumn{3}{c}{ Conv. } & \multicolumn{2}{c}{ Comp. } & \multicolumn{2}{c}{$\begin{array}{c}\text { Diferença } \\
\text { Conv. }- \text { Comp. }\end{array}$} & NS $^{1}$ \\
\cline { 2 - 10 } & P1 & P2 & P1 & P2 & P1 & P2 & P1 & P2 \\
\hline CMS (kg/dia) & 6,49 & 8,75 & 4,92 & 9,09 & $1,57 \pm 0,38$ & $-0,34 \pm 0,57$ & 0,0008 & 0,5600 \\
CMO (kg/dia) & 6,08 & 8,21 & 4,56 & 8,52 & $1,52 \pm 0,35$ & $-0,31 \pm 0,53$ & 0,0005 & 0,5733 \\
CFDN (kg/dia) & 4,35 & 5,61 & 3,32 & 5,83 & $1,03 \pm 0,26$ & $-0,22 \pm 0,48$ & 0,0010 & 0,6537 \\
CCT (kg/dia) & 4,80 & 6,53 & 3,39 & 6,72 & $1,41 \pm 0,38$ & $-0,19 \pm 0,57$ & 0,0002 & 0,6902 \\
CCSDN (kg/dia) & 1,47 & 2,16 & 0,85 & 2,16 & $0,63 \pm 0,35$ & $<0,01 \pm 0,53$ & $<0,0001$ & 0,9660 \\
CEM (Mcal/dia) & 19,79 & 27,83 & 14,46 & 29,30 & $5,33 \pm 0,96$ & $-1,47 \pm 1,86$ & $<0,0001$ & 0,4413 \\
\hline
\end{tabular}

${ }^{1}$ Nível de significância pelo teste $\mathrm{t}$ de Student.

Os animais submetidos ao sistema crescimento compensatório apresentaram menores CMS, CMO, CFDN, CCT, CCSDN (expressos em $\mathrm{kg} / \mathrm{dia}$ ) e CEM (expresso em Mcal/dia) durante o período de restrição (do primeiro ao $90^{\circ}$ dia do período experimental). No entanto, durante o período de realimentação (do $91^{\circ}$ ao $150^{\circ}$ dia), o consumo não foi diferente.
Os coeficientes de digestibilidade total da matéria seca (DMS), matéria orgânica (DMO) e dos carboidratos totais (DCT) foram mais altos no tratamento convencional e no tratamento com a inclusão de ionóforo na dieta (Tab. 3).

No rúmen, os ionóforos inibem bactérias grampositivas, alterando a fermentação ruminal, o que resulta em aumento da digestibilidade de 
nutrientes e, conseqüentemente, da disponibilidade de energia e nitrogênio dos alimentos para o organismo animal. Quando utilizados em doses efetivas, esses aditivos não alteram o consumo de matéria seca e de nutrientes em novilhas e vacas leiteiras (Osborne et al., 2004). Van Soest (1994) sugeriu que os ionóforos são mais efetivos na redução da digestibilidade da proteína bruta e da matéria orgânica em dietas que contêm fontes de concentrado rapidamente degradável do que em dietas à base de silagem e feno, uma vez que a proteína solúvel do feno e da silagem possui alta concentração de nitrogênio não-protéico em comparação ao concentrado.

A monensina também teve efeito positivo sobre a digestibilidade da FDN (Tab. 2). A suplementação com ionóforo na dieta com alta proporção de grãos, quando utilizada na alimentação de bovinos de corte (Cooper e Klopfenstein, 1996) e de vacas leiteiras no período de transição (Green et al., 1999), foi um meio efetivo de reduzir ou impedir a queda no $\mathrm{pH}$ ruminal proporcionada pela dieta. $\mathrm{O}$ aumento no $\mathrm{pH}$ pode promover um ambiente ruminal favorável ao crescimento de bactérias celulolíticas, ocasionando aumento na digestibilidade da fibra.

Dennis et al. (1981), ao avaliarem o efeito da suplementação com monensina sobre 0 crescimento de microrganismos ruminais, verificaram inibição do crescimento de quatro de sete sepas de bactérias produtoras de ácido lático, mas não encontraram alteração no número de microrganismos que utilizam esse substrato, sugerindo que a monensina pode causar diminuição na produção de lactato a partir de hexoses e manter a capacidade de metabolização do lactato para propionato.

Além de atuar sobre o $\mathrm{pH}$ ruminal, o ionóforo pode alterar o local de digestibilidade da fibra. Osborne et al. (2004) observaram que a monensina não alterou a digestibilidade dos nutrientes da dieta no ambiente ruminal, mas aumentou no trato digestivo total, evidenciando um incremento de digestibilidade no intestino delgado. Haïmound et al. (1995) constataram aumento da digestibilidade no trato digestivo pós-ruminal (intestino delgado), mas não verificaram modificação na digestibilidade no trato digestivo total.

Os dados encontrados na literatura indicam que os efeitos da monensina sobre a digestão dos nutrientes não são conclusivos. As razões para essas discrepâncias parecem ser a quantidade de ionóforo adicionada à dieta, a composição da dieta e o consumo de matéria seca (Mutsvangwa et al., 2002).

No período de realimentação, houve aumento na digestibilidade da matéria orgânica (DMO), da fibra em detergente neutro (DFDN), dos carboidratos totais (DCT) e dos carboidratos solúveis em detergente neutro (DCSDN) (Tab. 2).

Sabe-se que a redução do $\mathrm{pH}$ para níveis inferiores a 6,2 tem sido apontada como o principal fator químico responsável pela redução na digestibilidade da fibra (Casamiglia et al., 2002). Neste trabalho, o pH ruminal não foi estimado, mas, aparentemente, a dieta com relação volumoso:concentrado 50:50 do sistema de crescimento compensatório (período de realimentação) não reduziu o $\mathrm{pH}$ do líquido ruminal para níveis inferiores a esse limite, o que pode ter aumentado a digestibilidade da FDN.

Não houve efeito do sistema, da adição de ionóforo à dieta e do período sobre a produção microbiana (purinas microbianas absorvidas e $\mathrm{N}$ microbiano). A eficiência microbiana, expressa em g PB microbiana produzida por kg de NDT consumido, foi superior no período de restrição, quando comparado ao período de realimentação (Tab. 3). Zinn et al. (1994) verificaram diminuição da produção de proteína bacteriana no rúmen. A ação da monensina sódica sobre a produção microbiana tem variado de nula a negativa (Haïmound et al., 1995). Esses resultados podem ser atribuídos à concentração de cátion na dieta concentrada (Rumpler et al., 1986), à adaptação microbiana (Morris et al., 1990) e à concentração energética da dieta (Zinn, 1986). Goodrich et al. (1984) observaram que o ótimo valor de energia para que ocorra efetiva ação da monensina sódica é 2,9 Mcal EM/kg de MS. Neste experimento, o valor de EM foi de 2,28 a 2,42 Mcal $/ \mathrm{kg}$ de MS e pode ter sido o responsável pelo não efeito do ionóforo sobre a produção de proteína microbiana. 
Tabela 3. Médias e diferenças entre as fontes de variação para as digestibilidades da matéria seca (DMS), da matéria orgânica (DMO), da fibra em detergente neutro (DFDN), dos carboidratos totais (DCT) e dos carboidratos solúveis em detergente neutro (DCSDN), de acordo com os tratamentos

\begin{tabular}{|c|c|c|c|c|c|c|c|c|c|c|}
\hline \multirow[b]{2}{*}{ Item } & \multicolumn{3}{|c|}{ Sistema de manejo } & \multicolumn{3}{|c|}{ Ionóforo (I) } & \multicolumn{3}{|c|}{ Período (P) } & \multirow[b]{2}{*}{ Erro $^{2}$} \\
\hline & Conv. & Comp & $\begin{array}{l}\text { Conv - } \\
\text { Comp }\end{array}$ & Sem & Com & $\begin{array}{l}\text { Sem - } \\
\text { com }^{1}\end{array}$ & P1 & P2 & $\mathrm{P} 1-\mathrm{P} 2{ }^{1}$ & \\
\hline DMS (\%) & 70,89 & 68,17 & $\begin{array}{r}2,72 \\
(0,0006)\end{array}$ & 68,60 & 70,47 & $\begin{array}{r}-1,86 \\
(0,0133)\end{array}$ & 68,86 & 70,21 & $\begin{array}{r}-1,35 \\
(0,0659)\end{array}$ & 0,71 \\
\hline DMO (\%) & 71,94 & 69,42 & $\begin{array}{r}2,52 \\
(0,0007)\end{array}$ & 69,82 & 71,54 & $\begin{array}{r}-1,71 \\
(0,0160)\end{array}$ & 69,77 & 71,59 & $\begin{array}{r}-1,82 \\
(0,0112)\end{array}$ & 0,67 \\
\hline DFDN (\%) & 64,34 & 64,12 & $\begin{array}{r}0,21 \\
(0,7485)\end{array}$ & 63,46 & 65,00 & $\begin{array}{r}-1,53 \\
(0,0257)\end{array}$ & 63,05 & 65,41 & $\begin{array}{r}-2,35 \\
(0,0011)\end{array}$ & 0,66 \\
\hline DCT $(\%)$ & 70,84 & 67,02 & $\begin{array}{r}3,81 \\
(<0,0001)\end{array}$ & 68,02 & 69,84 & $\begin{array}{r}-1,82 \\
(0,0092)\end{array}$ & 67,25 & 70,61 & $\begin{array}{r}-3,37 \\
(<0,0001)\end{array}$ & 0,66 \\
\hline DCSDN (\%) & 93,37 & 93,39 & $\begin{array}{r}-0,02 \\
(0,9899)\end{array}$ & 92,94 & 93,81 & $\begin{array}{r}-0,87 \\
(0,6464)\end{array}$ & 90,22 & 96,54 & $\begin{array}{r}-6,32 \\
(0,0020)\end{array}$ & 1,88 \\
\hline
\end{tabular}

${ }^{1}$ Valores entre parênteses representam o nível de significância pelo teste $t$ de Student.

${ }^{2}$ Erro das estimativas das diferenças entre as fontes de variação.

Conv.: convencional; comp.: crescimento compensatório

Tabela 4. Médias e diferenças entre as fontes de variação para purinas microbianas absorvidas (PABS), nitrogênio microbiano (NMIC) e eficiência microbiana (EFIC), de acordo com os tratamentos

\begin{tabular}{|c|c|c|c|c|c|c|c|c|c|c|}
\hline \multirow[b]{2}{*}{ Item } & \multicolumn{3}{|c|}{ Sistema de manejo } & \multicolumn{3}{|c|}{ Ionóforo (I) } & \multicolumn{3}{|c|}{ Período } & \multirow[b]{2}{*}{ Erro $^{2}$} \\
\hline & Conv. & Comp. & $\begin{array}{l}\text { Conv. }-\overline{1} \\
\text { comp. }\end{array}$ & Sem & Com & $\begin{array}{l}\text { Sem- } \\
\text { Com }^{1}\end{array}$ & P1 & P2 & $\mathrm{P} 1-\mathrm{P} 2^{1}$ & \\
\hline $\begin{array}{l}\text { PABS } \\
\text { (g/dia) }\end{array}$ & 496,98 & 410,82 & $\begin{array}{r}86,15 \\
(0,0886)\end{array}$ & 495,94 & 411,86 & $\begin{array}{r}84,08 \\
(0,0962)\end{array}$ & 457,99 & 449,81 & $\begin{array}{r}8,17 \\
(0,8687)\end{array}$ & 49,05 \\
\hline $\begin{array}{l}\text { NMIC } \\
\text { (g/dia) }\end{array}$ & 361,33 & 298,69 & $\begin{array}{r}62,64 \\
(0,0886)\end{array}$ & 360,57 & 299,44 & $\begin{array}{r}61,10 \\
(0,0962)\end{array}$ & 332,98 & 327,04 & $\begin{array}{r}5,944 \\
(0,8687)\end{array}$ & 35,67 \\
\hline EFIC $^{1}$ & 82,67 & 80,08 & $\begin{array}{r}2,59 \\
(0,8078)\end{array}$ & 89,03 & 73,72 & $\begin{array}{r}15,31 \\
(0,1582)\end{array}$ & 100,43 & 62,32 & $\begin{array}{r}38,11 \\
(0,0011) \\
\end{array}$ & 66,18 \\
\hline
\end{tabular}

$\mathrm{EFIC}=\mathrm{g}$ PBmic $/ \mathrm{kg}$ NDT consumido

${ }^{1}$ Valores entre parênteses representam o nível de significância pelo teste $t$ de Student.

${ }^{2}$ Erro das estimativas das diferenças entre as fontes de variação.

Conv.: convencional; comp.: crescimento compensatório.

\section{CONCLUSÕES}

O manejo nutricional para crescimento compensatório em novilhas leiteiras e a suplementação com monensina sódica na dieta têm efeito positivo sobre a digestibilidade dos nutrientes. A utilização de monensina em dietas com 2,28 a 2,42 Mcal EM/kg de MS não causa alteração na produção de proteína microbiana. A relação EM:PB da dieta interfere na eficiência de produção microbiana de acordo com o NDT consumido.

\section{REFERÊNCIAS BIBLIOGRÁFICAS}

BECKETT, S.; LEAN, I.; DYSON, R. et al. Effects of monensin on the reproduction, health, and milk production of dairy cows. J. Dairy Sci., v.81, p.15631573, 1998.

CASAMIGLIA, S.; FERRET, A.; DEVANT, M. Effects of $\mathrm{pH}$ and $\mathrm{pH}$ fluctuations on microbial fermentation and nutrient flow from a dual-flow continuous culture system. J. Dairy Sci., v.85, p.574$579,2002$. 
CHEN, X.B.; GOMES, M.J. Estimation of microbial protein suplly to sheep and cattle based on urinary excretion of purine derivatives - an overview of technical details. Bucksburnd, Aberdeen: Rowett Research Institute, 1992. p.21. (Occasional publication).

CHIZZOTTI, M.L. Avaliação da casca de algodão para novilhos de origem leiteira e determinação da excreção de creatinina e produção de proteina microbiana em novilhas e vacas leiteiras. 2004. 132f. Dissertação (Mestrado) - Universidade Federal de Viçosa, Viçosa, MG.

COCHRAN, R.C.; ADAMS, D.C.; WALLACE, J.D. et al. Predicting digestibility of different diets with internal markers: evaluation of four potential markers. J. Anim. Sci., v.63, p.1476-1483, 1986.

COOPER, R.; KLOPFENSTEIN, T.J. Effect of Rumensin and feed intake variation on ruminal $\mathrm{pH}$. In: SCIENTIFIC UPDATE ON RUMENSIN/TYLAN/MICOTIL FOR THE PROFESSIONAL FEEDLOT CONSULTANT, 1996, Indianapolis. Proceedings... Indianapolis: Elanco Animal Health, 1996. p.A1-A14.

DENNIS, S.M.; NAGARAJARA, T.G.; BARTLEY, E.E. et al. Effects of lasalocid and monensin on lactato-producing or using rumen bacteria. J. Anim. Sci., v.52, p.418-426, 1981.

GOODRICH, R.D.; GARRET, J.E.; GAST, D.R. et al. Influence of monensin on the performance of cattle. $J$. Anim. Sci., v.58, p.1484-1498, 1984.

GREEN, B.L.; MCBRIDE, B.W.; SANDALS, W.D. et al. The impact of the monensin controlled release capsule upon subclinical acidosis in the transition dairy cow. J. Anim. Sci., v.82, p.333-342, 1999.

HAIIMOUND, D.A.; VERNAY, M.; BAYOURTHE, C. et al. Avoparcin and monensin effects on the digestion of nutrients in dairy cows fed a mixed diet. Can. J. Anim. Sci., v.75, p.379-385, 1995.

LEOPOLDINO, W.M.; LANA, R.P.; EIFERT, E.C. et al. Avaliação de ionóforos pela perda do potássio celular e produção de gases in vitro. Arq. Bras. Med. Vet. Zootec., v.59, p.1516-1522, 2007.

MORRIS, F.E.; BRANINE, M.E.; GAYLEAN, M.L. et al. Effect of rotating monensin plus tylosin and lasalocid on performance, ruminal fermentation, and site and extent of digestion in feedlot cattle. J. Anim. Sci., v.68, p.3069-3078, 1990.

MUTSVANGWA, T.; WALTON, J.P.; PLAIZIER, J.C. et al. Effects of a monensin controlled-release capsule or premix on attenuation of subacute ruminal acidosis in dairy cows. J. Anim. Sci., v.85, p.34543502, 2002.
NUTRIENT requirements of dairy cattle. 7.ed.Washington, DC: National Academy of Sciences, 2001.

ORELLANA, B.P.; BALCELLS, J.; MARTÍNORUE, S.M. et al. Excretion of purine derivates in cows: endogenous contribution and recovery of exogenous purine bases. Liv. Prod. Sci., v.68, p.243250,2001 .

OSBORNE, J.K.; MUTSVANQWA, T.; ALZAHAL, $O$. et al. Effects of monensin on ruminal forage degradability and total tract diet digestibility in lactating dairy cows during grain-induced sub acute ruminal acidosis. J. Anim. Sci., v.87, p.1840-1847, 2004.

PEREIRA, J.R.A.; ROSSI JR., P. Manual prático de avaliação de alimentos. Piracicaba: Fundação de Estudos Agrários Luiz de Queiroz, 1995. 25p.

RUMPLER, W.V.; JOHNSON, D.E.; BATES, D.B. The effect of high dietary cation concentration on methanogenesis by steers fed diets with and without ionophores. J. Anim. Sci., v.62, p.1737-1741, 1986.

RUSSELL, J.B.; STROBEL, H.J. Effect of ionophores on ruminal fermentation. Appl. Environ. Microbiol., v.55, p.1-6, 1989 .

SCHELLING, G. Monensin mode of action in the rumen. J. Anim. Sci., v.58, p.1518-1527, 1984.

SILVA, D.J.; QUEIROZ, A.C. Análises de alimentos: Métodos químicos e biológicos. 3.ed. Viçosa: UFV, 2002. 235p.

SPEARS, J.W. Ionophores and nutrient digestion and absorption in ruminants. J. Nutr., v.120, p.632-638, 1990.

USER'S guide: statistical analysis system - Version 8.12. Cary, NC: SAS Institute, 2000.

VALADARES, R.F.D.; BRODERICK, G.A.; CLAYTON, M.K. et al. Excretion of purine derivatives by Holstein cows abomasally infused with incremental amounts of purines. J. Dairy Sci., v.82, p.2686-2696, 1999.

VAN SOEST, P.J. Nutritional ecology of the ruminant. Ithaca: Cornell University, 1994. 476p.

VAN SOEST, P.J.; ROBERTSON, J.B.; LEWIS, B.A. Methods of dietary fiber, neutral detergent fiber, and nonstarch polysaccharides in relation to animal nutrition. J. Anim. Sci., v.74, p.3583-3597, 1991.

ZINN, R.A. Influence of forage level on response of feedlot steers to salinomycin supplementation. $J$. Anim. Sci., v.63, p.2005-2020, 1986.

ZINN, R.A.; PLASCENCIA, A.; BARAJAS, R. Interaction of forage level and monensin in diets for feedlot cattle on growth performance and digestive function. J. Anim. Sci., v.72, p.2209-2215, 1994. 